\section{The impact of acid mine drainage (AMD) on the distribution of selected radionuclides in the sediments of two pit lakes in the Muskau Arch (western Poland)
ILONA SEKUDEWICZ ${ }^{1}$, ŠÁRKA MATOUŠKOVÁ ${ }^{2}$, JAN ROHOVEC $^{2}$, KAROLINA KAUCHA ${ }^{1}$ AND MICHAE GĄSIOROWSKI $^{1}$ \\ ${ }^{1}$ Institute of Geological Sciences, Polish Academy of Sciences \\ ${ }^{2}$ Institute of Geology, Czech Academy of Sciences \\ Presenting Author: i.sekudewicz@twarda.pan.pl}

The study of the occurrence and circulation of radionuclides in the lake ecosystem is extremely important due to the potential migration of radioactive pollutants, as well as, the problems of dating lake sediments. The distribution of radioactive isotopes in the sediments might be strongly related to physicochemical processes that might occur in the sediment column. It might be especially important in the pits lakes affected by acid mine drainage (AMD), which is often associated with low water $\mathrm{pH}$ and high metal concentrations.

The main aim of the presented study was to determine the effect of the acidification and redox processes on the vertical distribution of ${ }^{238} \mathrm{U},{ }^{210} \mathrm{~Pb},{ }^{210} \mathrm{Po}$ and ${ }^{137} \mathrm{Cs}$ concentrations in the sediment column of two post-mining lakes in the area of the Muskau Arch (western Poland). The selected lakes are located in the pits formed as a result of lignite exploitation. The first lake is characterized by a water $\mathrm{pH}$ of around 5 and an anoxic condition occurring near the bottom. The second lake has a much lower water $\mathrm{pH}$ (around 3) and a higher dissolved oxygen level.

In order to achieve the research goal, the chemical composition of lake and pore water was measured using the ICPOES and ICP-MS. The content of total organic carbon (TOC) and total nitrogen (TN) in collected sediments was analysed using an elemental analyser. The activity concentration of ${ }^{210} \mathrm{Po}$ was measured by alpha spectroscopy, whereas ${ }^{210} \mathrm{~Pb}$ and ${ }^{137} \mathrm{Cs}$, by gamma spectroscopy. The obtained results showed that the distribution of ${ }^{210} \mathrm{Po}$ and ${ }^{210} \mathrm{~Pb}$ activity concentrations in the sediment column in both lakes differ significantly from the theoretical (exponential). Statistical analysis was performed to explain the observed disturbances and to identify possible factors and processes that may affect the distribution of studied radionuclides in selected post-mining lakes.

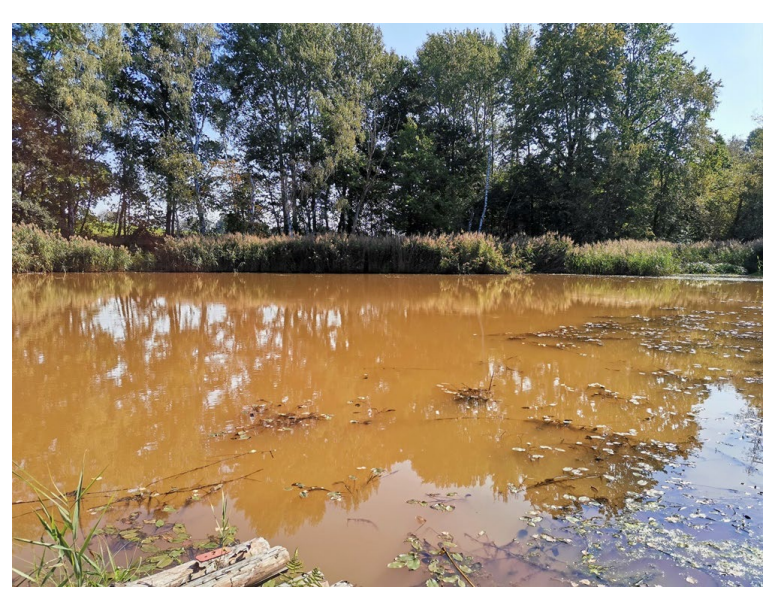

